\title{
Association of salivary levels of immunoglobulin-a and amylase with oral- dental manifestations in patients with controlled and non-controlled type 2 diabetes
}

Marjan Kheirmand Parizi ${ }^{1}$, Hamed Akbari ${ }^{2,3}$, Mahsa Malek-mohamadi ${ }^{4}$, Maryam Kheirmand Parizi ${ }^{5}$ and Shahla Kakoei ${ }^{6,7^{*}}$ (D)

\begin{abstract}
Background: Oral health is related to general health and one of the most prevalent chronic diseases is diabetes mellitus. Diabetes can have adverse effects on oral health and vice versa. Saliva analysis can be used as a non-invasive method to obtain information about diseases status like diabetes. The aim of present study was to evaluate the salivary immunoglobulin-A (s-lgA) and salivary amylase levels and their associations with oral-dental manifestations in patients with controlled and non-controlled type 2 diabetes.

Methods: This case-control study was carried out on 90 subjects who referred to the Diabetes Center of Shahid Bahonar Hospital, Kerman University of Medical Sciences, Kerman, Iran. Participants were divided into three groups: 1) uncontrolled diabetic patients $(n=30)$; 2) controlled diabetic patients $(n=30)$; and 3) healthy individuals $(n=30)$. Unstimulated salivary levels of I-A and amylase were measured. All participants underwent a dental and periodontal examination to explore the oral and dental manifestations. T-test, chi-square and ANOVA tests were used for data analysis in SPSS 18.
\end{abstract}

Results: Significant higher level of s-lgA was found in uncontrolled diabetic patients compared to controlled diabetic $(P \leq 0.0001)$ and the control group $(P=0.004)$. Moreover, the mean levels of $s$-amylase in uncontrolled patients was significantly higher compared to controlled diabetic $(P=0.01)$ and the control group $(P \leq 0.0001)$. Uncontrolled diabetic patients with oral candidiasis, erythematous candidiasis, abscesses, or xerostomia had higher s-lgA levels compared to the controlled diabetic participants. Moreover, uncontrolled diabetic patients with oral candidiasis or erythematous candidiasis showed a significant higher levels of s-amylase compared to controlled diabetic patients. Also, significant positive correlations were found between s-lgA and DMFT and s-lgA and PDI $(r=0.444, P=0.014$ and $r=0.386, P=0.035$, respectively).

Conclusion: In conclusion, higher s-amylase and s-IgA concentrations may reflect oral-dental manifestations in T2DM. Moreover, the current findings suggest that s-amylase and s-lgA may serve as a complementary and alternative fluid in screening for diabetes mellitus.

Keywords: Diabetes mellitus, Saliva, Salivary immunoglobulin-a, Salivary amylase, Oral manifestations

\footnotetext{
* Correspondence: skakoei@gmail.com

${ }^{6}$ Oral and Dental Diseases Research Center, Dental School, Kerman University

of Medical Sciences, Kerman, Iran

${ }^{7}$ Department of Oral Medicine, School of Dentistry, Kerman University of

Medical Sciences, Kerman, Iran

Full list of author information is available at the end of the article
}

(c) The Author(s). 2019 Open Access This article is distributed under the terms of the Creative Commons Attribution 4.0 International License (http://creativecommons.org/licenses/by/4.0/), which permits unrestricted use, distribution, and reproduction in any medium, provided you give appropriate credit to the original author(s) and the source, provide a link to the Creative Commons license, and indicate if changes were made. The Creative Commons Public Domain Dedication waiver (http://creativecommons.org/publicdomain/zero/1.0/) applies to the data made available in this article, unless otherwise stated. 


\section{Background}

Type 2 diabetes mellitus (T2DM) is a chronic and progressive disease threatening people throughout the world, particularly in developing countries $[1,2]$. Currently, T2DM is characterized by the World Health Organization (WHO) as the sixth leading cause of death globally, and it is estimated that 439 million adults will be affected by T2DM by the year 2030 [3]. Regardless of its prevalence, the hormonal changes, microvascular, macrovascular, and neuronal injuries associated with T2DM cause complications such as retinopathy, nephropathy, neuropathy, and oral-dental manifestations $[4,5]$. It has been well established that T2DM is associated with some oral cavities complications affecting the quality of life [6]. The most prevalent oral/dental complications include xerostomia, burning mouth syndrome, dental caries, tooth loss, periapical lesions, various infections, oral candidiasis, lichen planus, odontogenic abscess, taste disturbance, salivary glands dysfunction and specially periodontal diseases such as gingivitis and periodontitis [7, 8].

Accumulating evidence indicates that saliva is a noninvasive source for the detection of different oral and systemic conditions and is an essential fluid for protecting the dynamic environment of the oral cavity $[9,10]$. Some studies have shown that the permeability of basement membranes of the salivary glands are altered in diabetic patients [11-13]. Submandibular, parotid, and sublingual salivary glands are exocrine glands assigned to secreting saliva. The main components of salivary fluid are water, electrolytes, and proteins. Salivary proteins such as enzymes (amylase, lipase), albumin, immunoglobulin, glycoproteins, polypeptides, and oligopeptides play a critical role in oral health $[9,14]$.

Secretory IgA (s-IgA) is an antimicrobial defense agent against pathogens in the first line of the immune system, and it plays a major role in oral health [15]. It is noteworthy that previous investigations have merely evaluated IgA concentrations in uncontrolled diabetic patients; however, these studies have yielded conflicting results [16-20].

Amylase is a calcium-dependent enzyme found in saliva that breaks starch down into maltose and dextrin [21]. The greater penetration of proteins such as amylase in saliva due to changes in the base membrane permeability of the salivary glands is seen in diabetic patients, and some studies have shown a higher expression of amylase receptors in diabetes [22]. Considering these findings, the current study evaluated salivary amylase levels in controlled and uncontrolled diabetic patients. The results of studies by Kim [16] and by Prathibha [17] showed lower levels of amylase in diabetic objects, while the previous findings [18-20] reported higher amounts of s-amylase in the participants. Some other studies have declared no changes in s-amylase amounts in diabetic patients $[13,23]$.
The aims of the current study were first, to evaluate salivary IgA and amylase levels and their associations with diabetes; second, to compare the results of subjects with oral/dental manifestations among the controlled T2DM, uncontrolled T2DM, and healthy participants; and finally, to reveal the correlations between variables.

\section{Methods}

This case-control retrospective study was conducted on 30 uncontrolled diabetic patients $(10$ men and 20 women, mean age $=55.16 \pm 2.2$ years $), 30$ controlled diabetic patients (13 men and 17 women, mean age $=$ $50.76 \pm 1.97$ years), and 30 healthy individuals who were companions to patients or came for their annual checkups (14 men and 16 women, mean age $=49 \pm 1.4$ years) and referred to the Diabetes Center of Shahid Bahonar Hospital, Kerman University of Medical Sciences, Kerman, Iran from July to December, 2016.

The inclusion criteria were as follows: age above 30 yearsold, fasting for at least 8 hours before blood and saliva sampling. Unwilling participants, subjects suffering from severe diabetic complications or systemic diseases, smokers, cases of alcohol dependence and those who had received medications of other diseases for at least 4 weeks before study were excluded. According to the clinical data, participants were divided into three groups as follows: 1) uncontrolled diabetic $(n=30) ; 2)$ controlled diabetic $(n=30)$; and 3$)$ non-diabetic subjects as a control group $(n=30)$.

Participants with one of the following criteria were diagnosed as T2DM: 1) Fasting blood sugar (FBS) levels over $126 \mathrm{mg} / \mathrm{dl}$; 2) random blood glucose levels over $200 \mathrm{mg} / \mathrm{dl}$; 3) two-hour blood sugar levels over $120 \mathrm{mg} / \mathrm{dl}$; A random plasma glucose (PG) measurement of $\geq 200 \mathrm{mg} / \mathrm{dL}$ met the criteria for a diagnosis of T2DM in patients with classic symptoms of hyperglycaemic crisis (increased thirst, Blurred vision, Frequent urination, Increased hunger).

Numbness or tingling in the feet. Furthermore, patients receiving antidiabetic medication with $\mathrm{HbA} 1 \mathrm{C} \geq 6.5 \%$ were labeled as uncontrolled T2DM, while those with diabetes criteria and HbA1c $\leq 6.5 \%$ were considered as controlled T2DM [24]. Written informed consents were obtained from all participants. This study conforms to the Declaration of Helsinki [25] regarding research involving human subjects and approved by the ethics committee of Kerman University of Medical Sciences (IR.KMU.REC.1395.364).

Frequent abscesses, lesions and oral mucosa abnormalities including oral candidiasis manifestations (white plaque, erythematous candidiasis, thrush, angular cheilitis, median rhomboid glossitis and denture stomatitis) were evaluated in all participants with clinical diagnosis of calibrated examiner. The location of any noted lesions were recorded [8]. The number of decayed, missing and filled teeth (DMFT) was recorded using the World Health Organization (WHO) recommendations for assessing oral 
health [26]. In addition, periodontal status was evaluated using the periodontal disease index (PDI) as follows: three components of each six selected teeth (upper left central incisor and first premolar, first upper right molar, lower left first molar and lower right central incisor and first premolar) were evaluated separately. All participants were evaluated on tongue blade sign. Xerostomia was characterized using Fox et al. questionnaire [27].

First, participants were asked to rinse their mouth 3 times with filtered water. Then, unstimulated saliva samples were collected in the morning between 8 and 11 a.m. after $5 \mathrm{~min}$ of rest by spitting out to a sterile glass tubes. The samples were immediately taken to a laboratory and centrifuged (at $3000 \mathrm{rpm}$ for $15 \mathrm{~min}$ ). Then, supernatants were immediately frozen and stored at $20^{\circ} \mathrm{C}$. Salivary IgA concentration was measured in all participants by a commercially available enzyme-linked immunosorbent assay (ELISA) kit (Dia Metra, Milano, Italy). Experiments were carried out according to the manufacturer's protocol. Beside, salivary levels of amylase were analyzed using an automatic analyzer (TechniCon Systems Inc., California, USA). Demographic and clinical information was compiled using questionnaires.

\section{Statistical analysis}

Numerical variables were presented as mean \pm SEM (standard error of mean), while categorical variables were summarized as numbers (percentages). The KolmogorovSmirnov test was used to evaluate the distribution of quantitative variables. The variables were compared between two groups by Student's t-test and the Chi-square/ Fisher's Exact Test. Salivary levels of amylase and IgA were compared using one-way ANOVA with post-hoc Tukey multiple comparisons test across the three studied groups. Association between quantitative variables was assessed using Pearson's correlation coefficient (r). The statistical analyses were performed using the SPSS software version 18.0 for Windows (SPSS Inc., Chicago, IL). $P$-values $<0.05$ were considered statistically significant.

\section{Results}

The mean age of participants was $55.16 \pm 2.2,50.77 \pm$ 1.7 , and $49 \pm 1.4$ in uncontrolled diabetic, controlled diabetic and control group, respectively. There were no significant differences in age and sex among three groups ( $\mathrm{P}>0.05$ for both). Comparison of s-IgA among three studied groups are shown in Fig. 1. A significant difference of s-IgA level was found among three groups $(P \leq$ $0.0001)$. There was a significant higher level of s-IgA in uncontrolled diabetic patients compared to controlled diabetics $(P \leq 0.0001)$ and control subjects $(P=0.004)$. However, no significant difference was found between controlled diabetic and control subjects $(P=0.583)$.

Figure 2 shows the mean levels of s-amylase among three groups. There was a significant difference of s-amylase among three groups $(P \leq 0.0001)$. The mean levels of $\mathrm{s}$-amylase in uncontrolled patients showed significant differences compared to controlled diabetic $(P=0.01)$ and control subjects $(P \leq 0.0001)$. However, the mean levels of $\mathrm{s}$-amylase did not show significant differences between controlled diabetic and control subjects $(P=0.308)$.

Comparison of the mean levels of s-IgA and s-amylase with oral/dental manifestations among three studied groups are presented in Table 1. The mean levels of s-IgA and s-amylase in subjects with oral candidiasis were significantly different among three groups $(P=0.002$ and $P=$ 0.018 , respectively). The results of post-hoc Tukey test illustrated that the mean levels of s-IgA in uncontrolled

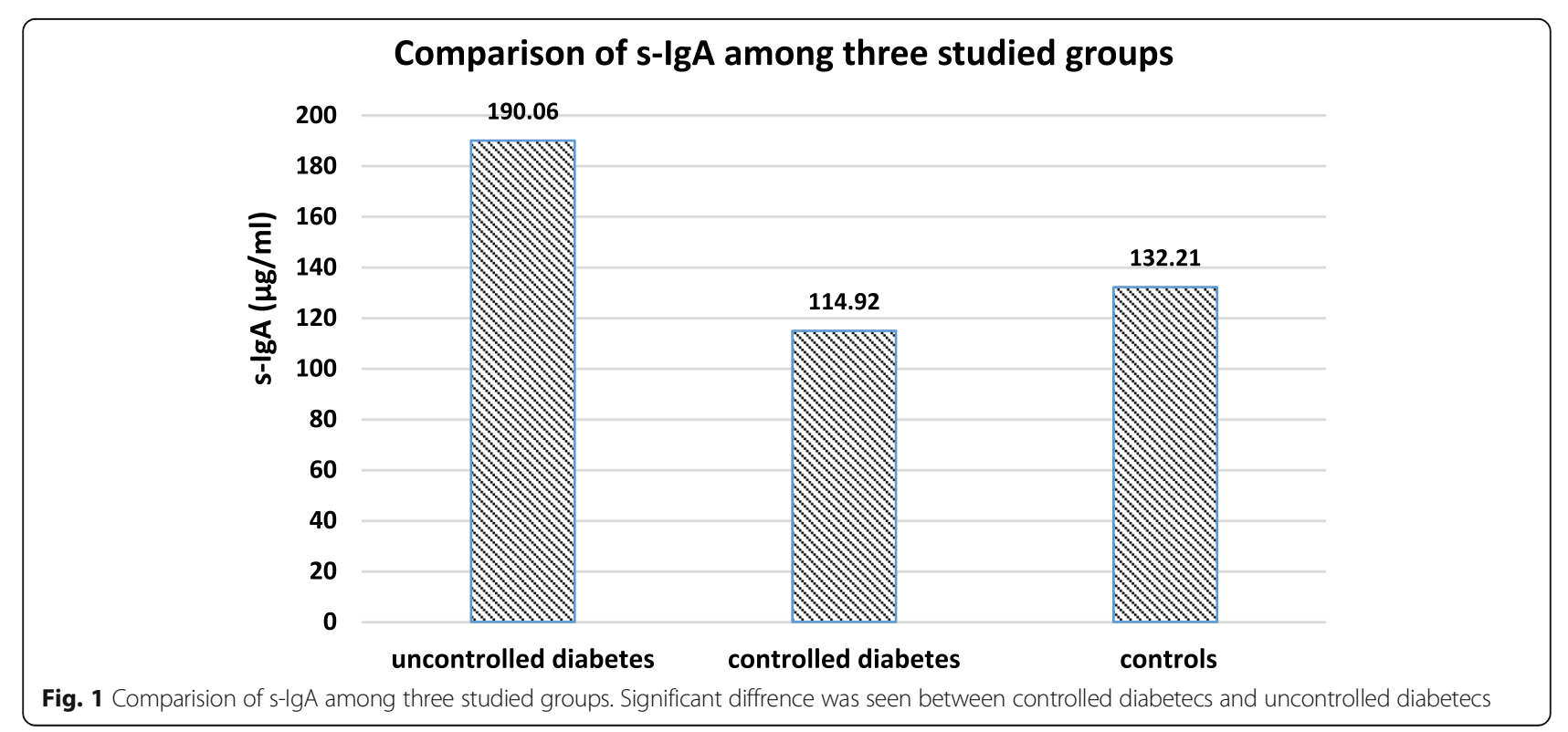




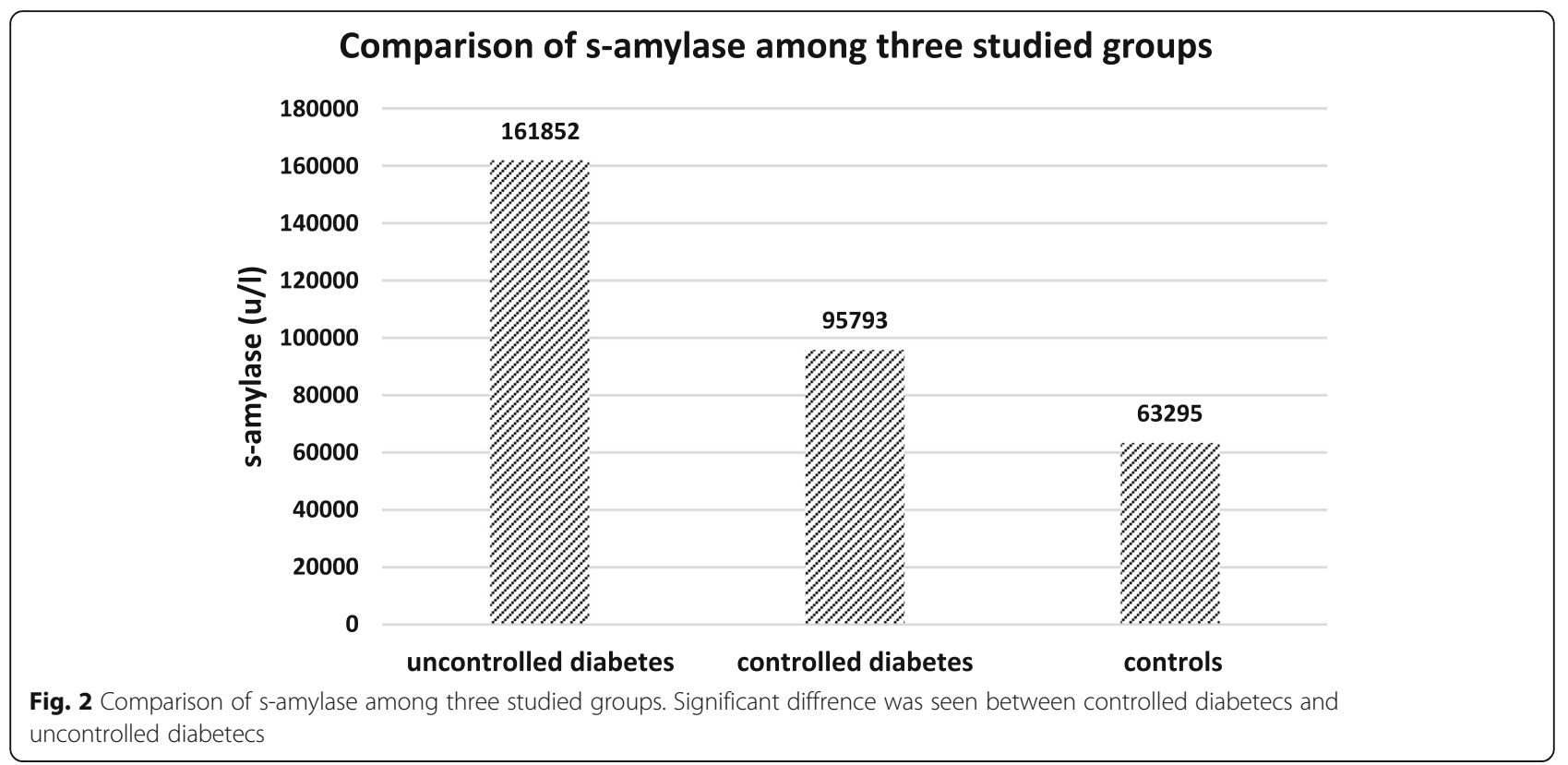

diabetic patients with oral candidiasis $(195.79 \pm 17.78)$ were significantly higher than controlled diabetic patients (98.13 \pm 10.67$)(P=0.003)$. Similarly, the mean levels of s-amylase in uncontrolled diabetic patients with oral candidiasis $(193,364.67 \pm 36,135.98)$ were significantly higher than controlled diabetic patients $(48,719.37 \pm 28$, 372) $(P=0.028)$. Uncontrolled diabetic patients $(210.76 \pm$ 13.12) with white plaques had significantly higher level of s-IgA compared to controlled diabetics $(81.83 \pm 22.68)$ $(P=0.013)$. The results revealed that controlled diabetic patients $(216,400 \pm 23,950.4)$ had significantly lower levels of s-amylase concentration compared to the uncontrolled $(25,150 \pm 2361.5)$ ones $(P=0.038)$ There was a significant difference in the mean levels of s-IgA between uncontrolled (221.98 \pm 39.76$)$ and controlled diabetic patients $(77.84 \pm 23.19)$ with abscesses $(P=0.022)$. Moreover, the mean levels of s-IgA in uncontrolled patients $(205.7 \pm$ 20.87) with xerostomia were significantly higher than those of controlled diabetics $(81.75 \pm 12.1)(P \leq 0.0001)$. Furthermore, no significant difference was found in s-IgA and s-amylase levels of subjects with trush or median rhomboid glossitis signs among three groups $(P>0.05)$. Since angular cheilitis manifestation was not observed in participants, hence, it was not investigated in the analyses.

Correlations among age, FBS, HbA1C, DMFT (Decayed, Missing, Filled Teeth), PDI (Periodontal Disease Index), sIgA, and s-amylase within controlled diabetic patients are illustrated in Table 2. Results show that there is a positive

Table 1 Comparison of the mean levels of s-lgA and s-amylase with oral/dental manifestations among the three studied groups

\begin{tabular}{|c|c|c|c|c|c|c|c|c|}
\hline \multirow{2}{*}{$\begin{array}{l}\text { Oral/dental } \\
\text { manifestations }\end{array}$} & \multicolumn{4}{|l|}{$s-\lg A$} & \multicolumn{4}{|l|}{ s-Amylase } \\
\hline & $\begin{array}{l}\text { uncontrolled } \\
\text { diabetic }\end{array}$ & $\begin{array}{l}\text { controlled } \\
\text { diabetic }\end{array}$ & control & $p$-value & $\begin{array}{l}\text { uncontrolled } \\
\text { diabetic }\end{array}$ & $\begin{array}{l}\text { controlled } \\
\text { diabetic }\end{array}$ & control & $p$-value \\
\hline Oral candidiasis & $195.79 \pm 17.78$ & $98.13 \pm 10.67^{*}$ & $107.52 \pm 32.69$ & 0.002 & $\begin{array}{l}193,364.67 \\
\pm 36,135.98\end{array}$ & $\begin{array}{l}48,719.37 \\
\pm 28372^{*}\end{array}$ & $\begin{array}{l}42,078.33 \\
\pm 30,461.78\end{array}$ & 0.018 \\
\hline White plaque & $210.76 \pm 13.12$ & $81.83 \pm 22.68$ & - & 0.013 & $\begin{array}{l}307,490 \\
\pm 175,903.1\end{array}$ & $\begin{array}{l}17,760.5 \\
\pm 1239.5\end{array}$ & - & 0.292 \\
\hline Erythematous candidiasis & $209.88 \pm 49.64$ & $110.26 \pm 23.2$ & - & 0.436 & $\begin{array}{l}216,400 \\
\pm 23,950.4\end{array}$ & $\begin{array}{l}25,150 \\
\pm 2361.5\end{array}$ & - & 0.038 \\
\hline Thrush & $221.85 \pm 33.63$ & $73.35 \pm 6.73^{*}$ & $172.85 \pm 8.3$ & 0.57 & $\begin{array}{l}136,500 \\
\pm 26,513.61\end{array}$ & $\begin{array}{l}138,037 \\
\pm 108,821\end{array}$ & $\begin{array}{l}12,035 \\
\pm 8651\end{array}$ & 0.254 \\
\hline Median rhomboid glossitis & $163.13 \pm 50.12$ & $121.48 \pm 16.93$ & $74.85 \pm 2.24$ & 0.215 & $\begin{array}{l}93,200 \\
\pm 37,900\end{array}$ & $\begin{array}{l}17,670 \\
\pm 3452.91\end{array}$ & $\begin{array}{l}57,100 \\
\pm 18,338.8\end{array}$ & 0.257 \\
\hline abscesses & $221.98 \pm 39.76$ & $77.84 \pm 23.19$ & - & 0.022 & $\begin{array}{l}284,466.66 \\
\pm 76,543.8\end{array}$ & $\begin{array}{l}100,500 \\
\pm 53,700\end{array}$ & 0.243 & 0.243 \\
\hline Xerostomia & $205.7 \pm 20.87$ & $81.75 \pm 12.1^{*}$ & $118.49 \pm 33.96$ & 0.0001 & $\begin{array}{l}189,807.6 \\
\pm 44,143.3\end{array}$ & $\begin{array}{l}59,417.2 \\
\pm 2463.08\end{array}$ & $\begin{array}{l}77,973.3 \\
\pm 26,897.8\end{array}$ & 0.065 \\
\hline
\end{tabular}

s-lgA, salivary immunoglobulin A; s-amylase, salivary amylase. * Significant difference with uncontrolled diabetes $(P<0.05)$. Significant at $<0.05$ levels 
Table 2 Correlations among age, FBS, HbA1C, DMFT, PDI, s-IgA, and s-amylase within controlled diabetic patients

\begin{tabular}{|c|c|c|c|c|c|c|c|c|}
\hline & & Age & FBS & $\mathrm{HbA1C}$ & DMFT & PDI & $s-\lg A$ & s-Amylase \\
\hline \multirow[t]{2}{*}{ Age } & Pearson's Correlation & 1.000 & -0.294 & -0.189 & 0.703 & 0.504 & 0.324 & -0.144 \\
\hline & $P$-value & - & 0.115 & 0.316 & .000 & .005 & 0.081 & 0.449 \\
\hline \multirow[t]{2}{*}{ FBS } & Pearson's Correlation & -0.294 & 1.000 & 0.429 & -0.278 & -0.154 & -0.057 & -0.222 \\
\hline & $P$-value & 0.115 & - & 0.018 & 0.137 & 0.415 & 0.766 & 0.239 \\
\hline \multirow[t]{2}{*}{$\mathrm{HbA} 1 \mathrm{C}$} & Pearson's Correlation & -0.189 & 0.429 & 1.000 & -0.135 & 0.064 & -0.141 & -0.166 \\
\hline & $P$-value & 0.316 & 0.018 & - & 0.478 & 0.736 & 0.457 & 0.381 \\
\hline \multirow[t]{2}{*}{ DMFT } & Pearson's Correlation & 0.703 & -0.278 & -0.135 & 1.000 & 0.694 & -0.41 & -0.112 \\
\hline & $P$-value & .000 & 0.137 & 0.478 & - & .000 & 0.83 & 0.555 \\
\hline \multirow[t]{2}{*}{ PDI } & Pearson's Correlation & 0.504 & -0.154 & 0.064 & 0.694 & 1.000 & -0.127 & -0.159 \\
\hline & $P$-value & .005 & 0.415 & 0.736 & .000 & - & 0.503 & 0.403 \\
\hline \multirow[t]{2}{*}{$s-\lg A$} & Pearson's Correlation & 0.324 & -0.057 & -0.141 & -0.41 & -0.127 & 1.000 & -0.022 \\
\hline & $P$-value & 0.081 & 0.766 & 0.457 & 0.83 & 0.503 & - & 0.909 \\
\hline \multirow[t]{2}{*}{ s-Amylase } & Pearson's Correlation & -0.144 & -0.222 & 0.166 & -0.112 & -0.159 & -0.022 & 1.000 \\
\hline & $P$-value & 0.449 & 0.239 & 0.381 & 0.555 & 0.403 & 0.909 & - \\
\hline
\end{tabular}

s-lgA, salivary immunoglobulin A; s-amylase, salivary amylase. Significant at $<0.05$ levels

correlation between age and DMFT and age and PDI $(\mathrm{r}=$ $0.703, P \leq 0.0001$ and $\mathrm{r}=0.504, P=0.005$, respectively). Also, a significant correlation was observed between DMFT and PDI $(\mathrm{r}=0.694, P \leq 0.0001)$. However, other correlations were too poor to affect each other.

Table 3 shows the correlations among age, FBS, HbA1C, DMFT, PDI, s-IgA, and s-amylase within uncontrolled diabetic patients. Significant positive correlations were found between age and FBS, DMFT, and PDI $(r=0.393, P=0.031, r=0.395, P=0.031$, and $r=0.536$, $P=0.002$, respectively). In addition, a significant positive correlation was seen between PDI and DMFT $(r=0.922$, $P \leq 0.0001)$. However, other correlations were not significantly different.
Table 4 illustrates the correlations among age, FBS, HbA1C, DMFT, PDI, s-IgA, and s-amylase within healthy subjects. Similar to two previous groups, a significant positive correlation was observed between age and DMFT and age and PDI in the control group $(\mathrm{r}=$ $0.641, \mathrm{P} \leq 0.0001$ and $\mathrm{r}=0.514, P=0.004$, respectively). Also, a significant positive correlation between DMFT and PDI was observed. A significant positive correlation was found between FBS and $\operatorname{HbA1C}(r=0.669, \mathrm{P} \leq$ 0.0001 ). Moreover, significant positive correlations were found between s-IgA and DMFT and s-IgA and PDI $(\mathrm{r}=$ $0.444, P=0.014$ and $\mathrm{r}=0.386, P=0.035$, respectively). However, no significant correlation was observed among other variables in the control group.

Table 3 Correlations among age, FBS, HbA1C, DMFT, PDI, s-lgA, and s-amylase within uncontrolled diabetic patients

\begin{tabular}{|c|c|c|c|c|c|c|c|c|}
\hline & & Age & FBS & $\mathrm{HbA1C}$ & DMFT & PDI & $S-\lg A$ & S-Amylase \\
\hline \multirow[t]{2}{*}{ Age } & Pearson's Correlation & 1.000 & 0.393 & 0.152 & 0.395 & 0.536 & 0.018 & -0.271 \\
\hline & $P$-value & - & 0.031 & 0.423 & 0.031 & 0.002 & 0.923 & 0.148 \\
\hline \multirow[t]{2}{*}{ FBS } & Pearson's Correlation & 0.393 & 1.000 & 0.015 & 0.067 & 0.058 & -0.181 & -0.293 \\
\hline & $P$-value & 0.031 & - & 0.939 & 0.723 & 0.762 & 0.338 & 0.116 \\
\hline \multirow[t]{2}{*}{$\mathrm{HbA1C}$} & Pearson's Correlation & 0.152 & 0.015 & 1.000 & -0.037 & 0.031 & 0.039 & 0.172 \\
\hline & $P$-value & 0.423 & 0.939 & - & 0.846 & 0.873 & 0.837 & 0.362 \\
\hline \multirow[t]{2}{*}{ DMFT } & Pearson's Correlation & 0.395 & 0.067 & -0.037 & 1.000 & 0.922 & -0.061 & -0.321 \\
\hline & $P$-value & 0.031 & 0.723 & 0.846 & - & 0.000 & 0.749 & 0.084 \\
\hline \multirow[t]{2}{*}{ PDI } & Pearson's Correlation & 0.536 & 0.058 & 0.031 & 0.922 & 1.000 & -0.017 & -0.256 \\
\hline & $P$-value & 0.002 & 0.762 & 0.873 & 0.000 & - & 0.927 & 0.172 \\
\hline \multirow[t]{2}{*}{$s-\lg A$} & Pearson's Correlation & 0.018 & -0.181 & 0.039 & -0.061 & -0.017 & 1.000 & 0.147 \\
\hline & $P$-value & 0.923 & 0.338 & 0.837 & 0.749 & 0.927 & - & 0.438 \\
\hline \multirow[t]{2}{*}{ s-Amylase } & Pearson's Correlation & -0.271 & -0.293 & 0.172 & -0.321 & -0.256 & 0.147 & 1.000 \\
\hline & $P$-value & 0.148 & 0.116 & 0.362 & 0.084 & 0.172 & 0.438 & - \\
\hline
\end{tabular}

s-lgA, salivary immunoglobulin A; s-amylase, salivary amylase. Significant at $<0.05$ levels 
Table 4 Correlations among age, FBS, HbA1C, DMFT, PDI, s-lgA, and s-amylase within healthy subjects

\begin{tabular}{|c|c|c|c|c|c|c|c|c|}
\hline & & Age & FBS & $\mathrm{HbA} 1 \mathrm{C}$ & DMFT & PDI & $s-\lg A$ & s-Amylase \\
\hline \multirow[t]{2}{*}{ Age } & Pearson's Correlation & 1.000 & -0.135 & -0.255 & 0.641 & 0.514 & 0.307 & -0.142 \\
\hline & $P$-value & - & 0.478 & 0.174 & 0.000 & 0.004 & 0.099 & 0.455 \\
\hline \multirow[t]{2}{*}{ FBS } & Pearson's Correlation & -0.135 & 1.000 & 0.669 & 0.011 & -0.039 & 0.05 & 0.096 \\
\hline & $P$-value & 0.478 & - & 0.000 & 0.953 & 0.836 & 0.791 & 0.613 \\
\hline \multirow[t]{2}{*}{$\mathrm{HbA1C}$} & Pearson's Correlation & -0.255 & 0.669 & 1.000 & -0.108 & -0.258 & -0.055 & -0.096 \\
\hline & $P$-value & 0.174 & 0.000 & - & 0.570 & 0.168 & 0.774 & 0.613 \\
\hline \multirow[t]{2}{*}{ DMFT } & Pearson's Correlation & 0.641 & 0.011 & -0.108 & 1.000 & 0.720 & 0.444 & -0.125 \\
\hline & $P$-value & 0.000 & 0.953 & 0.570 & - & 0.000 & 0.014 & 0.512 \\
\hline \multirow[t]{2}{*}{ PDI } & Pearson's Correlation & 0.514 & -0.039 & -0.258 & 0.720 & 1.000 & 0.386 & -0.127 \\
\hline & $P$-value & 0.004 & 0.836 & 0.168 & 0.000 & - & 0.035 & 0.504 \\
\hline \multirow[t]{2}{*}{$s-\lg A$} & Pearson's Correlation & 0.307 & 0.05 & -0.055 & 0.444 & 0.386 & 1.000 & 0.203 \\
\hline & $P$-value & 0.099 & 0.791 & 0.774 & 0.014 & 0.035 & - & 0.281 \\
\hline \multirow[t]{2}{*}{ s-Amylase } & Pearson's Correlation & -0.142 & 0.096 & -0.096 & -0.125 & -0.127 & 0.203 & 1.000 \\
\hline & $P$-value & 0.455 & 0.613 & 0.613 & 0.512 & 0.504 & 0.281 & - \\
\hline
\end{tabular}

s-lgA, salivary immunoglobulin A; s-amylase, salivary amylase. Significant at $<0.05$ levels

\section{Discussion}

Findings of the present study demonstrated that salivary IgA and amylase levels are associated with diabetes. Moreover, s-IgA levels are associated with T2DM in patients with oral candidiasis, white plaque, abscesses, or xerostomia manifestations, while s-amylase levels are associated with T2DM in patients with oral candidiasis or erythematous candidiasis manifestations.

Alterations in oral/dental manifestations and salivary secretions have been proposed in the development, symptomatology, and severity of some systemic diseases such as diabetes [1]. Various studies have evaluated alterations in salivary amylase and IgA levels in diabetic patients and have yielded conflicting results $[5,8,13,20$, 28 ]. To the best of the authors' knowledge, no study has yet investigated the association of salivary levels of Ig-A and amylase with oral/dental manifestations in patients with uncontrolled and controlled T2DM. Therefore, this study measured unstimulated saliva to evaluate IgA and amylase levels and their associations with oral/dental manifestations among 30 patients with uncontrolled T2DM, 30 patients with controlled T2DM, and 30 control subjects.

In the present study, significantly higher levels of sIgA were observed in the uncontrolled diabetic patients compared to the controlled diabetic and the healthy subjects. It is plausible that increased mean levels of s-IgA are caused by the presence of plaque, calculus, and infection in the diabetic patients in this study. These findings were in agreement with those of previous studies [27, 29-33]. Conversely, Salles et al. [34] reported a lower s-IgA concentration in diabetic patients compared to non-diabetic individuals, which is probably related to the non-homogeneous gender distribution and the use of both T1DM and T2DM patients in their research. Another study conducted by Bhuyan et al. [35] demonstrated lower level of s-IgA in diabetic patient's specially uncontrolled diabetic ones. Moreover, others found no significant differences $[5,28,36]$. However, none of them compared the s-IgA among controlled T2DM, uncontrolled T2DM and healthy subjects separately. These discrepancies in findings may be explained by variations in saliva collection methods (stimulated vs. unstimulated), disease stages, genetic susceptibility, or study design and measuring methods, e.g., the inclusion of three groups (uncontrolled T2DM, controlled T2DM, and healthy participants) vs. two groups (diabetic and non-diabetic participants) as study populations, or the use of ELISA method to measure s-IgA vs. immunoturbidimetric or immunonephelometric methods.

The current findings showed no significant difference of s-amylase levels between the controlled diabetic group and the healthy control group. However, a significantly higher concentration of s-amylase in the uncontrolled diabetic group was observed compared to other two groups. This finding supports the previous studies [18-20,37] . While Yavuzimaz et al. [32] and Prathibha et al. [17] reported significant decreases in s-amylase levels in controlled diabetic patients when compared with healthy subjects. However, other studies showed no significant difference which was not consistent with the current results $[13,23,38]$. It is postulated that increased permeability of salivary glands basement membranes leads to the higher levels of s-amylase in diabetic groups. These discrepancies could be attributed to the differences in genetic susceptibility, case matching and measuring techniques. Therefore, further research is required to clarify the exact mechanisms. 
Previous studies have been investigated the association of salivary components, such as Ig-A, with different oral conditions $[3,6,8,35]$. In the current study, uncontrolled diabetic patients with oral candidiasis, white plaque, abscesses, or xerostomia had higher s-IgA levels compared to the controlled diabetic participants; however, no significant differences were observed between the uncontrolled diabetic patients and the healthy participants. A leading mechanism proposed to explain the increased levels of $\mathrm{s}$ IgA which may be due to the fact that T2DM affects the stimulation of immune response and secretion of s-IgA as a result of oral-dental disturbance. Our previous study showed higher levels of s-IgA in diabetic patients [8], while s-IgA was significantly lower in diabetic patients with oral candidiasis compared to healthy subjects and no significant differences were found among other oral-dental manifestations between two groups.

The salivary enzyme alpha-amylase mainly acts in the digestion of carbohydrates. It also has an important role in mucosal immunity by inhibiting the bacteria function [39]. In the current study, uncontrolled diabetic patients with oral candidiasis or erythematous candidiasis showed significant higher levels of s-amylase compared to controlled diabetic patients with the mentioned oral manifestations, however, no significant differences were found between uncontrolled diabetic patients and healthy subjects. The increased levels of s-amylase in uncontrolled diabetic patients may be explained by the increase of oral-dental manifestations to inhibit the microorganism function [40-42].

Previous studies documented that the risk of destructive periodontitis and other oral-dental manifestations is increased in T2DM $[43,44]$. In agreement with other reports [43-45], the present study demonstrated that both patients with uncontrolled and controlled T2DM had poorer health in some oral-dental conditions compared to the control group subjects (results are not shown). Thus, more comprehensive and regular oral-dental assessments at an early stage would be imperative in these patients.

An impressive body of evidence supports the concept that oral-dental conditions are generally worsened by increasing age [46-48]. As expected, a significant positive correlation was observed between age and DMFT and age and PDI in each of the three studied groups; this result is compatible with those of previous studies $[8,49]$. Towards this end, a significant positive correlation was found between DMFT and PDI in each three studied groups. Furthermore, significant positive correlations were observed between s-IgA and DMFT and s-IgA and PDI in healthy subjects; this result was in accordance with our previous study which had showed that s-IgA had been positively correlated with PDI [8]. No significant correlation was seen between s-IgA and the other variables in the uncontrolled and controlled diabetic groups; this result was in contrast with those of the authors' previous study which had showed positive correlations between s-IgA and HbA1C, DMFT, and PDI in diabetic patients [8]. It is noteworthy that no significant correlation was found between s-amylase and other variables in the three studied groups. Given the few studies regarding the correlation of $\mathrm{s}$-amylase and other factors, further studies are highly recommended to assess these correlations.

The cost-effectiveness, accessibility, and non-invasive characteristics of saliva samples are the most important advantages of using this body fluid for screening and diagnosing various metabolic diseases $[5,50]$. Moreover, previous studies documented that saliva fluid is an accurate and reliable tool for comparing blood measurements $[1,5]$.

It is well known that genetic background has an important impact on s-IgA and s-amylase levels. Moreover, individual diet can directly affect s-IgA and s-amylase levels. Likewise, the secretion and synthesis of s-IgA and s-amylase are strongly regulated by the neuroendocrine system; hence, neuroendocrine-related factors such as stress, physical activity, psychosocial conditions, and menstrual cycle may affect s-IgA and s-amylase levels $[49,51,52]$. Nevertheless, further longitudinal studies with a larger population are highly recommended to support the findings of the present study.

\section{Conclusion}

Higher s-amylase and s-IgA concentrations may reflect oral-dental manifestations in T2DM. Moreover, the current findings suggest that s-amylase and s-IgA may serve as a complementary and alternative fluid in screening diabetes mellitus.

\section{Abbreviations}

DMFT: number of decayed, missing and filled teeth; ELISA: enzyme-linked immunosorbent assay; FBS: Fasting blood sugar; HbA1C: hemoglobin A1C; PDI: periodontal disease index; PG: plasma glucose; S-amylase: salivary amylase; S-IgA: salivary immunoglobulin-A; T2DM: Type 2 diabetes mellitus; WHO: World Health Organization

\section{Acknowledgments}

We would like to thank Dr. Gholamreza Asadikaram and Mitra Shadkam for their valuable helps during the study.

\section{Authors' contributions}

Marjan Kh-P, Sh. K. and M. M-M designed the study, wrote the draft and did the data collection and the submission. $\mathrm{H}$. A. conducted laboratory analysis and Maryam Kh-P helped in data analysis. All authors contributed to writing and revising the final manuscript. All authors read and approved the final manuscript.

\section{Funding}

This work was supported by grants from Kerman University of Medical Sciences. The authors appreciate the support of the dissertation grant. The funding agency had no role in the design of the study, data collection and analysis or presentation of results.

Availability of data and materials

The datasets used and analyzed during the current study are available from the corresponding author on reasonable request. 


\section{Ethics approval and consent to participate}

This study has been approved by the Ethical Board Committee of Kerman Medical University in accordance with the Helsinki Declaration (IR.KMU.REC.1395.364). Written informed consent has been obtained from the participants prior to data collection process and, the data were anonymized before analysis.

\section{Consent for publication}

Not applicable.

\section{Competing interests}

The authors declare that they have no competing interests.

\section{Author details}

${ }^{1}$ Dentist, Student Research Committee, School of Dentistry, Kerman University of Medical Sciences, Kerman, Iran. ${ }^{2}$ Endocrinology and Metabolism Research Center, Institute of Basic and Clinical Physiology Sciences, Kerman University of Medical Sciences, Kerman, Iran. ${ }^{3}$ Department of Biochemistry, School of Medicine, Kerman University of Medical Sciences, Kerman, Iran. ${ }^{4}$ Community Oral Health Department, School of dentistry, Shahid Beheshti University of Medical Sciences, Tehran, Iran. ${ }^{5}$ Student Research Committee, Shahid Beheshti University of Medical Sciences, Tehran, Iran. ${ }^{6}$ Oral and Dental Diseases Research Center, Dental School, Kerman University of Medical Sciences, Kerman, Iran. ${ }^{7}$ Department of Oral Medicine, School of Dentistry, Kerman University of Medical Sciences, Kerman, Iran.

\section{Received: 13 March 2019 Accepted: 29 July 2019}

\section{Published online: 06 August 2019}

\section{References}

1. Lima-Aragão MW, de Oliveira-Junior Jde J, Maciel MCG, Silva LA, do Nascimento FRF, Guerra RNM. Salivary profile in diabetic patients: biochemical and immunological evaluation. BMC Res Notes. 2016;9(1):103.

2. Parirokh M, Eghbal MJ, Ghoddusi J, Kakoei S, Haghdoost AA, Kakooei S. The frequency of medically compromised patients in endodontic offices in Iran. Iran Endod J. 2013:8(2):48-51.

3. Shaw JE, Sicree RA, Zimmet PZ. Global estimates of the prevalence of diabetes for 2010 and 2030. Diabetes Res Clin Pract. 2010;87(1):4-14

4. Batbayar B, Somogyi J, Zelles T, Feher E. Immunohistochemical analysis of substance $P$ containing nerve fibres and their contacts with mast cells in the diabetic rat's tongue. Acta Biol Hung. 2003;54(3-4):275-83.

5. Bakianian Vaziri $P$, Vahedi M, Mortazavi H, Abdollahzadeh S, Hajilooi M. Evaluation of salivary glucose, IgA and flow rate in diabetic patients: a casecontrol study. J Dent (Tehran). 2010;7(1):13-8.

6. Kakoei SH, Navabi N, Aghaabbasi SHHM. Oral health related quality of life in patients with diabetes mellitus type 2 in the year 2012. J Oral Heal Oral Epidemiol. 2016:5(4):186-91.

7. Mauri-Obradors E, Estrugo-Devesa A, Jané-Salas E, Viñas M, López-López J. Oral manifestations of Diabetes Mellitus. A systematic review. Medicina oral, patologia oral y cirugia bucal. 2017 Sep;22(5):e586.

8. Kakoei S, Hosseini B, Haghdoost A, Sanjari M, Gholamhosseinian A, Afshar VFN. Evaluation of salivary secretory immunoglobulin a levels in diabetic patients and association with Oral and dental manifestations. Sultan Qaboos Univ Med J. 2015;15(4):507-11.

9. Cunha-correia AS, Lima DP, Lima A, Anjos DOS. USE OF SALIVA FOR DIAGNOSIS OF ORAL AND SYSTEMIC DISEASES. Rev Reg Araçatuba. 2014; 35(1):55-9.

10. Almeida PV. Saliva Composition and Functions. J comtemporary Dent Pract. 2008;9(3):72-80.

11. Edgar W. Saliva: its secretion, composition and functions. Br Dent J. 1992; 172(8):305-12

12. Burket L, Greenberg MS, Glick M, Ship J. Burket's Oral Medicine. PMPH-USA; 2008.

13. Panchbhai AS, Degwekar SS, Bhowte RR. Estimation of salivary glucose, salivary amylase, salivary total protein and salivary flow rate in diabetics in India. J Oral Sci. 2010;52(3):359-68.

14. Lee $\mathrm{YH}$, Wong DT. Saliva: an emerging biofluid for early detection of diseases. Am J Dent. 2009;22(4):241-8.

15. Marcotte H, Lavoie MC. Oral microbial ecology and the role of salivary immunoglobulin a. Microbiol Mol Biol Rev. 1998;62(1):71-109.
16. Kim SK, Cuzzort LM, McKean RK, Allen ED. Effects of diabetes and insulin on a-amylase messenger RNA levels in rat parotid glands. J Dent Res. 1990; 69(8):1500-4.

17. Prathibha MK. Evaluation of salivary profile among adult type 2 diabetes mellitus patients in South India. J Clin Diagnostic Res. 2013;7(8):1592-5.

18. Dodds MW, Dodds AP. Effects of glycemic control on saliva flow rates and protein composition in non-insulin-dependent diabetes mellitus. Oral Surg Oral Med Oral Pathol Oral Radiol Endod. 1997:83(4):465-70.

19. Aydin S. A comparison of ghrelin, glucose, alpha-amylase and protein levels in saliva from diabetics. J Biochem Mol Biol. 2007:40(1):29-35.

20. Malathi L, Masthan KMK, Balachander N, Aravindha Babu N, Rajesh E. Estimation of salivary amylase in diabetic patients and saliva as a diagnostic tool in early diabetic patients. J Clin Diagnostic Res. 2013;7(11):2634-6.

21. Fried M, Abramson S, Meyer JH. Passage of salivary amylase through the stomach in humans. Dig Dis Sci. 1987;32(10):1097-103.

22. Border MB, Schwartz S, Carlson J, Dibble CF, Kohltfarber H, Offenbacher S, et al. Exploring salivary proteomes in edentulous patients with type 2 diabetes. Mol BioSyst. 2012;8(4):1304-10

23. Carda C, Mosquera-Lloreda N, Salom L. Gomez de Ferraris ME PA. Structural and functional salivary disorders in type 2 diabetic patients. Med Oral Patol Oral y Cir Bucal. 2006:11(4):309-14.

24. American Diabetes Association. Diagnosis and classification of diabetes mellitus. Diabetes Care. 2010;33(SUPPL.1):62-9.

25. World Health Organisation. Declaration of Helsinki world medical association declaration of Helsinki ethical principles for medical research involving human subjects. J Am Med Assoc. 2013;310(20):2191-4.

26. World Health Organization. Oral health surveys: basic methods. 3rd ed. Geneva, Switzerland: WHO Press; 1997.

27. Fox PC, Busch KA, Baum BJ. Subjective reports of xerostomia and objective measures of salivary gland performance. J Am Dent Assoc. 1987;115(4):581-4.

28. Ahmadiafshar A, Mohsenifard MR, Mazloomzadeh S. Evaluation of serum \& salivary IgA in patients with type 1 diabetes. PLoS One. 2015:10(4):1-7.

29. Ardekani AM, Karbassi MH, Ardekani JM, Akhondinasab F, Mohammad MHM. Evaluation of salivary lgA in diabetic and non-diabetic patients: a case-control study. Iran J diabetes Obes. 2012;4(4):167-71.

30. Ben-Aryeh H, Cohen M, Kanter Y, Szargel R, Laufer D. Salivary composition in diabetic patients. J Diabet Complicat. 1988;2(2):96-9.

31. Harrison $\mathrm{R}$, Bowen WH. Flow rate and organic constituents of whole saliva in insulin-dependent diabetic children and adolescents. Pediatr Dent. 1987; 9(4):287-91.

32. Yavuzyilmaz E, Yumak O, Akdoğanli T, Yamalik N, Ozer N, Ersoy FYI. The alterations of whole saliva constituents in patients with diabetes mellitus. Aust Dent J. 1996;41(3):193-7.

33. Dodds MW, Yeh CKJD. Salivary alterations in type 2 (non-insulin-dependent) diabetes mellitus and hypertension. Community Dent Oral Epidemiol. 2000; 28(5):373-81.

34. Branco-de-Almeida LS, Alves CMC, Lopes FF, Pereira Ade FV, Guerra RNM, Pereira ALA. Salivary IgA and periodontal treatment needs in diabetic patients. Braz Oral Res. 2011:25(6):550-5.

35. Bhuyan SK, Mody RN, Bhuyan R. Estimation and comparison of serum and salivary lgA levels in controlled, uncontrolled diabetics and normal individuals. J Indian Acad oral Med Radiol. 2011;23(4):548.

36. Javed F, Sundin U, Altamash M, Klinge B, EngstrÖm PE. Self-perceived oral health and salivary proteins in children with type 1 diabetes. J Oral Rehabil. 2009:36(1):39-44.

37. Reznick AZ, Shehadeh N, Shafir Y, Nagler RM. Free radicals related effects and antioxidants in saliva and serum of adolescents with type 1 diabetes mellitus. Arch Oral Biol. 2006;51(8):640-8.

38. Newrick PG, Bowman C, Green D, O'Brien IAD, Porter SR, Scully C, et al. Parotid salivary secretion in diabetic autonomic neuropathy. J Diabet Complicat. 1991;5(1):35-7.

39. Rohleder N, Wolf JM, Maldonado EF, Kirschbaum C. The psychosocial stressinduced increase in salivary alpha-amylase is independent of saliva flow rate. Psychophysiology. 2006;43(6):645-52.

40. Scannapieco FA, Torres G, Levine MJ. Salivary alpha-amylase: role in dental plaque and caries formation. Crit Rev Oral Biol Med. 1993:4(3-4):301-7.

41. Shugars DC, Wahl SM. The role of the oral environment in HIV-1 transmission. J Am Dent Assoc. 1998:129(7):851-8.

42. Fabian TK, Hermann P, Beck A, Fejerdy P, Fabian G. Salivary defense proteins: their network and role in innate and acquired oral immunity. Int J Mol Sci. 2012;13(4):4295-320. 
43. Sandberg GE, Sundberg HE, Fjellstrom CA, Wikblad KF. Type 2 diabetes and oral health a comparison between diabetic and non-diabetic subjects. Diabetes Res Clin Pract. 2000;50(1):27-34.

44. Kawamura M, Fukuda S, Kawabata K, Iwamoto Y. Comparison of health behaviour and oral/medical conditions in non-insulin-dependent (type II) diabetics and non-diabetics. Aust Dent J. 1998:43(5):315-20.

45. Naito M, Yuasa H, Nomura Y, Nakayama T, Hamajima N, Hanada N. Oral health status and health-related quality of life: a systematic review. J Oral Sci. 2006:48(1):1-7.

46. Ghezzi EM, Ship JA. Systemic diseases and their treatments in the elderly: impact on oral health. J Public Health Dent. 2000;60(4):289-96.

47. Taylor GW, Loesche WJ, Terpenning MS. Impact of oral diseases on systemic health in the elderly: diabetes mellitus and aspiration pneumonia. J Public Health Dent. 2000;60(4):313-20.

48. Jainkittivong A, Aneksuk V, Langlais RP. Oral mucosal conditions in elderly dental patients. Oral Dis. 2002;8(4):218-23.

49. Teeuw W, Bosch JA, Veerman ECAA. Neuroendocrine regulation of salivary IgA synthesis and secretion: implications for oral health. Biol Chem. 2004; 385(12):1137-46.

50. Kaufman E, Lamster IB. The diagnostic applications of saliva-a review. Crit Rev Oral Biol Med. 2002;13(2):197-212.

51. Schumacher S, Kirschbaum C, Fydrich T, Ströhle A. Is salivary alpha-amylase an indicator of autonomic nervous system dysregulations in mental disorders? - a review of preliminary findings and the interactions with cortisol. Psychoneuroendocrinology. 2013;38(6):729-43.

52. Nater UM, La Marca R, Florin L, Moses A, Langhans W, Koller MM, et al. Stress-induced changes in human salivary alpha-amylase activity - associations with adrenergic activity. Psychoneuroendocrinology. 2006;31(1):49-58.

\section{Publisher's Note}

Springer Nature remains neutral with regard to jurisdictional claims in published maps and institutional affiliations.

Ready to submit your research? Choose BMC and benefit from:

- fast, convenient online submission

- thorough peer review by experienced researchers in your field

- rapid publication on acceptance

- support for research data, including large and complex data types

- gold Open Access which fosters wider collaboration and increased citations

- maximum visibility for your research: over $100 \mathrm{M}$ website views per year

At BMC, research is always in progress.

Learn more biomedcentral.com/submissions 